\title{
Luta pública contra o trabalho infantil doméstico: implicações democráticas das ações de advocacy
}

\author{
Public struggle against domestic child labor: democratic implications \\ of advocacy
}

Ao pé do casarão mal iluminado fatal foi pensares que ofereciam vida nova, pois ouviste os sinos. A família dormia ainda. Soubeste logo que havia menino, que havia menina, um doutor e sua mulher a quem devias servir, branca e alta mulher. [...] Mas ao ouvir a voz "Ó pequena", desabalada era a tua carreira pelas escadas, era a hora de retirar o urinol de porcelana com a urina da branca senhora que ficou roxa um dia porque te pegou dizendo "pêra lá que eu vou tirá o mijo da mulhé" e te trancou e quase te esmagou na porta para que consertasses a língua, Ó pequena! Terias que dizer "fazer o meu serviço, cumprir minha obrigação" aprendeste logo sem compreender. Maria Lúcia Medeiros (1990, p. 11-12)

O conto "Velas. Por quem?", de Maria Lúcia Medeiros, ilustra as aflições e vivências de gerações e gerações de brasileiros - ou melhor, brasileiras - pouco consideradas quando se trata da história de nosso país. A menina, cria da casa, agregada, vai crescendo à sombra dos patrões e a serviço deles. O conto relata a vida de uma garota que vive à mercê das "bulinações" dos patrões, pai e filho, e que é passada "como herança" à filha da patroa quando esta morre. A menina é retratada como aquela que teve a vida roubada e que "aprendeu como cachorro de sítio a sair com o rabo entre as pernas repetindo 'sim, senhora”; ou é representada ainda como um "cachorro fiel", sem condições de reação ou contestação:

É professora do Programa de Pós-Graduação em Comunicação, Linguagens e Cultura da Universidade da Amazônia (Unama) e colaboradora do Programa de Pós-Graduação em Comunicação da Universidade Federal do Pará (UFPA). E-mail: <danilagentilcal@gmail.com>. 
"fatal foi tua mansidão de bicho: o búfalo, a corça e o cão" (Medeiros, 1990, p. 12).

Ao final do conto, fica claro que a doméstica, já senhora, está tendo sua "sorte" lida por uma quiromante que conclui: "não vejo mais - pesada hora - rastro sequer de fortuna, perdeu-se a do coração [...] fatal foi te roubarem a linha da vida" (Medeiros, 1990, p. 13). Segundo Amarilis Tupiassu (2005, p. 312), essa prosa destaca "a representante do sem nenhum direito, desprovida de qualquer identidade social, um resto apenas, que sobrou da avassalagem dos antigos descimentos ${ }^{1}$, hoje ainda um pesadelo em processo, não só lance da memória que dói”. Apesar de retratar uma situação do início do século $\mathrm{XX}$, esse conto permanece contemporâneo naquilo que revela do cotidiano de muitas famílias e de meninas no Estado do Pará, mas também em todo o Brasil2 ${ }^{2}$. A iniciação de meninas no trabalho doméstico ocorre como uma preparação para a realização dessas tarefas em sua futura casa. Nesse sentido, as habilidades desenvolvidas na execução desse tipo de serviço não são reconhecidas como dignas de valor, já que existe certa naturalização dessas atividades como femininas em contraponto à ideia de que são competências adquiridas (Alberto et al., 2009). Corrobora essa "invisibilidade" do problema a ambiguidade constituinte da relação entre patrões e a menina agregada, que oscila entre ser serviçal ou se sentir parte da família (Motta-Maués, 2012).

Neste artigo, tomamos como objeto de estudo o trabalho infantil doméstico (TID), prática enraizada socialmente em nosso país, em que as relações de dominação ocorrem preponderantemente entre mulheres (patroas) e meninas (trabalhadoras) (Cal, 2007; Maia e Cal, 2014; Motta-Maués, 2012) e evidenciam constrangimentos estruturais relacionados à gênero, à classe e à raça. Na medida em que o cerne da dominação se dá entre mulheres (patroa/empregada), o que as distingue e alimenta essa relação de poder são elementos ligados à classe e à raça (Maia e Cal, 2014). O modo como esse tipo de trabalho infantil tem sido enfrentado no Brasil, por meio de

Referência à chamada "indústria da descida ou descimentos", um tipo de expedição ao interior da floresta para escravizar indígenas (Lamarão, 2008).

Segundo a Pesquisa Nacional por Amostra de Domicílios (Pnad), referente a 2011 e divulgada pelo IBGE em 2012, há no Brasil 257.691 crianças e adolescentes de 10 a 17 anos trabalhando como domésticas (MPT, 2013). No entanto, acreditamos ser esse número subestimado tanto pela natureza do tipo de pesquisa realizado (por amostragem), como pela dificuldade de caracterizar boa parte do serviço doméstico realizado por meninos e, sobretudo, meninas como "trabalho". A respeito das críticas sobre os dados oficiais do TID, ver também Jacquemin (2006). 
ações de advocacy, também é um terreno fértil para análises sobre gênero, democracia e desigualdades. De acordo com Luis Felipe Miguel (2014), os advocates se atribuem o papel de porta-vozes públicos de indivíduos e grupos. Contudo, adverte o autor, "formas de representação como advocacy, embora possam trazer benefícios em curto prazo para integrantes de um ou outro grupo social, não estimulam o exercício dessas autonomias [coletiva e individual]" (p. 264).

É neste último ponto que focamos o presente artigo. Objetiva-se, assim, tensionar os limites da atuação de grupos de advocacy no enfrentamento ao TID no contexto brasileiro em relação a um dos desafios democráticos apontados por Flávia Biroli (2013, p. 15), referente à contradição entre a democracia como valor e prática e "a tolerância social às relações de comando e subordinação”. De modo mais específico, reflete-se sobre a atuação pública, essencialmente midiática, desses grupos e a tematização das desigualdades que atuam como obstáculos à autodeterminação das meninas e mulheres envolvidas nesse tipo de trabalho infantil. Consideramos os media, compreendidos como um subsistema social que engloba o conjunto de instituições midiáticas, inclusive jornalísticas ${ }^{3}$, ambientes privilegiados para o questionamento de hierarquias sociais e de valor (Maia, 2014; Maia e Cal, 2014).

Com fortes contornos históricos e culturais, o TID é definido como uma das atividades laborais mais opressivas e mais negligenciadas (Aragão-Lagergren, 2003; Lamarão, 2008; Hasan e Saleem, 2013). É um problema social e político envolto em desigualdades de gênero e classe, e cujas relações de comando e subordinação são toleradas socialmente, em especial na região Norte do país (Lamarão, 2008; Cal, 2007, 2014; Motta-Maués, 2008). O próprio ambiente no qual o TID se realiza, o lar, é marcado por relações de poder, que estabelecem quem pode falar e ordenar e quem deve obedecer (Weber, 1991), e no qual as mulheres - e, podemos acrescentar, as crianças - costumam ser mais assujeitadas e oprimidas (Okin, 2008).

O enfrentamento do TID no Brasil tem ocorrido principalmente por intermédio de ações de advocacy desenvolvidas por atores locais e organismos internacionais. Esse processo foi iniciado por entidades e grupos que

O sistema dos media possui regras e modos operatórios próprios e goza de relativa autonomia em relação a outros sistemas sociais, como o econômico e o político. Diz-se "uma relativa autonomia" porque há constrangimentos sociais, técnicos, econômicos e profissionais aos quais os media estão sujeitos (Marques, 2008; Maia, 2011, 2012). 
advogavam pelos direitos de crianças e adolescentes num contexto social em que essa prática era largamente aceita (Cedeca-Emaús, 2002). Apesar da contribuição do advocacy para colocar em discussão temas e políticas, há uma tensão entre o que se diz em nome dos representados e o que seriam seus interesses efetivos. Para Miguel (2014, p. 262), “a substituição gerada por mecanismos de advocacy pode obstaculizar esse processo [desenvolvimento de demandas políticas pelo próprio grupo], trabalhando contra a autonomia dos grupos". Uma das faces dessa situação ocorre em grande medida porque as vozes e os discursos que ganham ressonância na esfera pública são de agentes de advocacy e não dos sujeitos concernidos.

Especialistas e atores sociais são normalmente tidos como fontes mais adequadas para falar publicamente em nome de crianças e adolescentes do que eles próprios (Miguel, 2011, 2014; Earls, 2011). Esse dilema tende a influenciar a forma como a luta contra o TID é tornada pública pelas organizações sociais e pelos media.

Este artigo também investiga especificamente o processo de advocacy contra o TID no Pará ${ }^{4}$, onde organizações sociais, locais e internacionais, empreenderam ações sistemáticas de enfrentamento durante toda a última década. Examinamos a cobertura dos dois principais jornais locais sobre o TID no período de 2000 a $2009^{5}$ (O Liberal e o Diário do Pará) com o objetivo de analisar: (1) a natureza das desigualdades relacionadas ao TID; (2) os lugares de fala e os posicionamentos de meninas e mulheres envolvidas com o TID; e (3) a relação apresentada entre os agentes de advocacy e as afetadas.

\section{Trabalho infantil doméstico como uma prática tolerada}

Diversos fatores históricos e sociais alimentam a aceitação social do trabalho infantil doméstico, por exemplo: a escravidão e o costume de trazer meninas de áreas rurais para estudar na capital e morar em casas de família; a concepção de que meninas devem assumir as tarefas domésticas como

\footnotetext{
No início dos anos de 2000, Belém (PA) foi escolhida por organizações internacionais (Unicef - Fundo das Nações Unidas para a Infância, e OIT - Organização Internacional do Trabalho) como cidade-sede de um projeto-piloto de enfrentamento ao TID. As cidades de Belo Horizonte (MG) e Recife (PE) também desenvolveram projetos-piloto nessa área.

Foram selecionados os jornais locais de maior expressão porque o interesse deste artigo reside no contexto local de enfrentamento ao TID, já que em Belém foi desenvolvido um projeto pioneiro contra esse tipo de trabalho. As matérias coletadas correspondem ao período de janeiro de 2000 a dezembro de 2009, que compreende a década de atuação das organizações sociais paraenses e internacionais contra esse problema.
} 
naturais da condição feminina e, portanto, como não trabalho; e por ocorrer nas casas de família, distante, assim, dos olhares públicos (Lamarão, 2008; Lamarão, Menezes e Ferreira, 2000; OIT, 2004; Hoyos, 2000; Blagbrough, 2008; Alberto et al., 2009; Cal, 2007).

Na história do país, é frequente a referência ao fato de meninas, filhas de escravos, terem sido levadas para as casas dos senhores para lhes servir de domésticas (Silva, 2009; Lamarão, 2008). Naquela época, "trabalhar era sinônimo de aprender a ser escravo" (Alberto et al., 2009, p. 59), de aprender a obedecer e a servir ao senhor.

No Pará, especificamente, desde o período colonial, mulheres e meninas escravas já trabalhavam dentro das casas dos senhores cuidando dos filhos deles, realizando todo tipo de serviço doméstico e, não raro, sofrendo abusos sexuais por parte dos patrões. Essa situação reforçou o ciclo de pobreza e a falta de qualificação, uma vez que, após a escravidão, essas mulheres passaram a ser criadas ou domésticas e trocavam sua força de trabalho por comida ou baixas remunerações (Alberto et al., 2009).

As feições atuais do TID, segundo Maria Luiza Lamarão (2008, p. 65), ainda guardam resquícios daquele período histórico, sobretudo no que se refere ao recrutamento das meninas por um intermediário, ou ainda às meninas entregues diretamente pelas famílias. Também são resquícios daquela época o afastamento da convivência familiar e comunitária e os impactos que a mudança para a cidade geram na vida de crianças e adolescentes.

Para Cláudia Fonseca (1995), os caminhos que as crianças percorrem - ou são levadas a percorrer - têm relação com a concepção de infância espraiada pelo contexto social em que os pais estão inseridos. Nesse sentido, a classe média em geral parte da ideia de que a criança é um "adulto em formação" e que, portanto, merece atenção seu desenvolvimento emocional e intelectual. A criança, assim, "é inserida em uma estratégia familiar de ascensão socioeconômica a longo termo" (Fonseca, 1995, p. 30) ${ }^{6}$. Nas classes baixas, o entendimento prioritário é o da criança "como adulto incompetente". O trabalho dos pais ou responsáveis, desse modo, é "assegurar que certas necessidades 'objetivas' sejam atendidas” (idem, p. 31).

Motta-Maués (2012) ressalta que a prática de circulação de crianças não é específica das classes populares. Nas mais abastadas, por exemplo, a circulação de crianças é frequente para a realização de cursos (línguas, reforço escolar) e atividades físicas, o que faz com que tenham uma "vida agendada", além da circulação entre casa da mãe, casa do pai, no caso de famílias separadas. 
O TID na casa de terceiros se apresenta, então, como uma possibilidade concreta de a criança ou adolescente frequentar uma família com melhores condições socioeconômicas - ainda que, por vezes, apenas ligeiramente melhores do que as de sua família de origem - e de suprir "necessidades" imediatas relacionadas à sobrevivência, mas também à aquisição de bens de consumo. Na nova família, a posição subalterna da menina criada ou agregada em relação aos patrões e às outras crianças da casa é evidente e, geralmente, não questionada (Fonseca, 1995; Lamarão, 2008; Carneiro e Rocha, 2009).

Para Fonseca (1995), embora essa menina, não raras vezes, receba o tratamento de "filha de criação", não haveria ambiguidade na relação familiar porque os patrões quase nunca são chamados de pais e sim de "senhor fulano de tal" ou "Seu/Dona”. Entretanto, outros autores (Lamarão, Menezes e Ferreira, 2000; Cal, 2007; Motta-Maués, 2012) afirmam que a ambiguidade dessa relação consiste em ora fazer parte da família - sobretudo, como uma relação entre madrinha/afilhada - e ora ser a empregada da casa ou a babá. A condição se torna clara em situações típicas, por exemplo, quando "ser da família" justifica o não pagamento de salário ou o pagamento de uma quantia mínima, enquanto o "não ser da família” fica evidente nos momentos de lazer, nos quais, normalmente, a menina doméstica fica responsável pela arrumação, por cuidar das crianças ou carregar as bagagens enquanto os outros "membros" da família têm como única "responsabilidade" aproveitar esses momentos.

Maria Angélica Motta-Maués (2008) aponta um traço de gênero que marca uma forte diferença entre "crias" meninas e meninos, qual seja, quando se trata de meninas, essas são criadas com a obrigação "quase natural" de executar serviços domésticos nos lares em que vivem e ainda continuam servindo por gerações a mesma família. Aos meninos, todavia, é reservado outro tipo de postura e comportamento. Eles são criados para buscar a vida fora de casa e como agregados temporários àquela família. A principal ocorrência é de meninas na situação de "cria" ou de "filha de criação". Para a autora, "é justamente seu estatuto localizado, esdruxulamente, entre essas duas categorias ['cria' e 'filha de criação'], que dá à 'cria' um perfil e uma posição particulares na já longa história de sua presença nos lares da Amazônia” (Motta-Maués, 2008, p. 168).

Nem todas as trabalhadoras infantis domésticas são "crias" no sentido desenvolvido por Motta-Maués (2008, 2012); no entanto, essa é uma das faces mais antigas a respeito da complexa relação entre famílias empregadoras e meninas domésticas. De acordo com Maria Luiza Marcílio (2003, p. 70), que 
desenvolveu uma extensa pesquisa histórica sobre crianças abandonadas no Brasil (no período 1726-1950), "a prática de criar filhos alheios sempre, e em todos os tempos, foi amplamente difundida e aceita no Brasil. São inclusive raras as famílias brasileiras que, mesmo antes de existir o estatuto da adoção, não possuíam um filho de criação em seu seio". Ser "filha de criação" implica um dever moral perante aquela família, cuja generosidade de "pegar para criar" filhos dos outros é sempre ressaltada. Além disso, qualquer comportamento da "cria" considerado inadequado por parte dessa família é enquadrado como uma forma de ingratidão (Fonseca, 1995; Motta-Maués, 2008; Lamarão, 2008).

Entrelaçada a esses fatores históricos e culturais, está também a falta de percepção do trabalho doméstico como um trabalho propriamente dito. Conforme Biroli (2013), há uma invisibilização do trabalho doméstico realizado por mulheres. Assim, sendo o TID uma atividade executada preponderantemente por meninas, estaria ligado a certa obrigação feminina de cuidar dos afazeres da casa e das crianças. Essa percepção é compartilhada, por vezes, pelas próprias adolescentes trabalhadoras que se consideram "desocupadas" (Hoyos, 2000). A inserção no trabalho doméstico ocorre, então, como se fosse uma imposição de gênero e um tipo de serviço mais próximo da realidade das meninas envolvidas (Lamarão, Menezes e Ferreira, 2000).

Outro modo pelo qual o TID não é visto como trabalho se baseia na sua realização como forma de aprendizagem das tarefas de reprodução e também como uma contribuição à rotina da casa, ainda que exija esforço e tenha longas jornadas (Alberto et al., 2009, p. 59).

Para enfrentar esse tipo de trabalho infantil, organizações sociais, sobretudo internacionais, iniciaram no começo dos anos de 2000 processos de advocacy nos contextos internacional, nacional e local, como detalharemos na seção seguinte.

\section{Advocacy contra o trabalho infantil doméstico}

No Brasil, a discussão sobre o trabalho infantil doméstico só entrou na agenda social a partir de $1999^{7}$ e, principalmente, na primeira metade da década de 2000. O debate se beneficiou de uma já articulada rede de orga-

O relatório da OIT (2003) sobre boas práticas no enfrentamento do trabalho infantil cita uma experiência pontual que ocorreu entre 1993 e 1995, no município de Campos dos Goitacazes (RJ), para o enfrentamento de 50 casos de TID, executada pelo Ipec/OIT em parceria com o governo municipal, mas que não gerou repercussão mais ampla. 
nizações internacionais e nacionais de combate ao trabalho infantil. Nessa época, apesar de já estarem tematizadas publicamente a necessidade e a importância da erradicação do trabalho infantil de modo geral, não havia um debate nacional sobre as atividades exercidas por crianças e adolescentes em casas de família.

A própria construção da expressão "trabalho infantil doméstico", que começa a ganhar visibilidade nesse período, é resultado da politização do tema advinda da atuação de organizações sociais pelo seu enfrentamento (Cal, 2007; Unicef, 1999). Isso porque, como vimos anteriormente, essa atividade não era reconhecida como trabalho, dificuldade que permanece ainda hoje. E as formas de nomeá-la variavam, entre outras expressões, como "dar uma ajuda" e "reparar menino". Além disso, as crianças e adolescentes que exerciam essa função eram chamadas de "crias da casa", "meninas da casa", "afilhadas", e não de trabalhadoras domésticas.

Desse modo, o enfrentamento ao TID no país ocorreu principalmente por ações e projetos de advocacy, desenvolvidos por atores locais e nacionais de forma conjunta com organismos internacionais, entre os quais a Organização Internacional do Trabalho (OIT), o Fundo das Nações Unidas para a Infância (Unicef) e a organização inglesa Save the Children, que apoia projetos em várias partes do mundo. Ações de advocacy são estratégias comumente utilizadas por organizações sociais e organismos internacionais como ações de defesa ou de promoção de determinada causa ou demanda (Libardoni, 2000). Assim, no caso do TID, esse processo foi iniciado por entidades e grupos que advogavam pelos direitos de crianças e adolescentes envolvidos nesse tipo de trabalho, num contexto social em que sua prática era largamente aceita (Cedeca-Emaús, 2002).

De acordo com Marlene Libardoni (2000, p. 208), advocacy diz respeito a:

[...] iniciativas de incidência ou pressão política, de promoção e defesa de uma causa e/ou interesse, e de articulações mobilizadas por organizações da sociedade civil com o objetivo de dar maior visibilidade a determinadas temáticas ou questões no debate público e influenciar políticas visando à transformação da sociedade.

Rennan Mafra (2014, p. 198) constrói de modo detalhado a trajetória desse conceito e ressalta que advocacy tanto "carrega uma possibilidade de sentido voltada a designar ações de sujeitos que assumem uma causa não 
ligada diretamente a suas próprias experiências do vivido" quanto pode designar ações empreendidas por sujeitos afetados pela causa advogada, mas que têm como intuito representar outros tantos que passaram pelas mesmas situações ou vivenciam os mesmos tipos de problema. $\mathrm{O}$ modo preponderante pelo qual o enfrentamento ao TID foi articulado condiz com a primeira acepção do termo.

Apesar da contribuição dos grupos de advocacy para colocar em discussão temas e políticas que objetivam garantir ou promover direitos de determinados grupos que detêm, por vezes, pouco poder de influência, há uma tensão entre o que se diz em nome desses grupos e o que seriam seus interesses efetivos. Para Miguel (2011), existe o risco de ações de advocacy se tornarem autoritárias ou paternalistas porque, em geral, quem ganha expressão pública são os agentes de advocacy e não os concernidos. Nesse sentido, de acordo com o autor, é fundamental que esses grupos ou agentes de advocacy se mantenham em diálogo com os sujeitos que desejam representar. Em suas palavras:

[...] os advocates promovem uma forma de substituição que faz com que a autoexpressão dos dominados deixe de aparecer como um problema a ser enfrentado. Afinal, seus direitos ou interesses já se fazem ouvir, defendidos por grupos e indivíduos melhor capacitados (Miguel, 2011, p. 54).

A nosso ver, essa tensão tende a repercutir na forma como a luta contra o TID é tornada pública pelas organizações sociais e pelos media. Tomamos como uma das nossas hipóteses de trabalho o fato de que o espaço destinado à fala e ao posicionamento de meninas e mulheres afetadas pelo TID nos media destina-se, principalmente, à expressão do sofrimento e das mazelas relacionadas ao trabalho infantil. Assim, as discussões mais políticas, sobretudo acerca de direitos e interesses, seriam atribuídas a especialistas e representantes de organizações sociais.

Casos de advocacy acerca da infância e da adolescência trazem desafios particulares à "autoexpressão dos dominados". Especialistas e advocates geralmente são considerados atores mais apropriados e com mais possibilidade de repercussão para falar em nome de crianças e adolescentes do que eles próprios (Miguel, 2011; Earls, 2011). Para Felton Earls (2011), a cidadania de crianças e adolescentes é garantida pelo fato de nascerem em um Estado, 
em um país. No entanto, somente são considerados cidadãos de fato, com direito à voz, quando adquirem o direito de votar, de modo que as decisões sobre o bem-estar de meninos e meninas são sempre atribuídas a figuras de autoridade, capazes de definir os seus "melhores interesses".

Earls, contudo, questiona posicionamentos dessa natureza e defende que a maturidade política tem relação com a capacidade de agir em conjunto em prol do bem comum. Segundo ele, "mesmo que às crianças seja negado o acesso aos processos eleitorais, elas têm opiniões, preferências e capacidades para deliberação e ação social" (Earls, 2011, p. 11; tradução nossa). Alisson James (2011) corrobora essa perspectiva acrescentando que a cidadania de crianças e adolescentes é aperfeiçoada à medida que eles deixam de ser considerados incompetentes ou irresponsáveis e passam a ser vistos como sujeitos capazes e com responsabilidades.

Apesar do enfrentamento ao TID ter sido iniciado pelas ações de advocacy de organizações internacionais, consta na maior parte dos guias e manuais que norteavam essas ações a necessidade de criar espaços de investigação sobre as condições de vida de meninos e, especialmente, de meninas trabalhadoras domésticas. Além disso, era clara a indicação para que esse tipo de processo envolvesse o protagonismo de adolescentes. Outra recomendação era para que os programas de enfrentamento ao TID fossem liderados por organizações locais e nacionais, de preferência em parceria com grupos de mulheres, organizações não governamentais e entidades ligadas à defesa dos direitos humanos (Black, 2002). Com isso, esperava-se que a iniciativa se beneficiasse de redes já organizadas nos países, envolvidas com a garantia dos direitos de mulheres e crianças, pois o TID tensiona, como dissemos, aspectos fundamentais de gênero.

No Brasil, o assunto entrou em pauta a partir de seminários internacionais e nacionais realizados por organizações sociais e também depois da produção de pesquisas sobre o TID (aspectos legais, sociais e culturais, estatísticas etc.) de abrangência nacional e local, financiadas principalmente por organismos internacionais e realizadas por pesquisadores brasileiros. Como mencionado, esse foi um importante aspecto da advocacia internacional contra o TID: envolver atores locais nas pesquisas e nas ações de enfrentamento. Outras diretrizes, como construir discursos de enfrentamento com base em contextos locais, estão bem claras nos documentos internacionais. Por exemplo: 
O trabalho infantil doméstico é uma questão que influencia a vida particular e familiar das pessoas, as realidades econômicas locais, os costumes e os valores socioculturais. Para destacar os danos que pode fazer às crianças, é necessário mostrar um espelho para as pessoas e pedir que examinem suas atitudes diante de várias coisas, incluindo a hierarquia social e infância. A advocacia é mais eficaz quando os atores locais assumem o papel principal. Os papéis principais de campanhas de advocacia devem ser o de romper com a invisibilidade atitudinal dessa prática e reduzir os casos de abuso e exploração (Unicef, 1999, p. 11; tradução nossa).

Em geral, as ações desses organismos internacionais se basearam na realização e promoção de campanhas com o objetivo de estimular mudanças culturais e de atitudes em relação ao TID; na realização de programas e projetos de intervenção para a retirada de meninas desse tipo de atividade e para prevenir a inserção de crianças e adolescentes no trabalho infantil doméstico; em incentivos e orientações para a elaboração de políticas específicas de enfrentamento; na geração de informações e dados estatísticos sobre essa modalidade de trabalho infantil para subsidiar intervenções e disseminar conhecimentos sobre as consequências do trabalho infantil doméstico; e também no fortalecimento das organizações locais e nacionais envolvidas no enfrentamento dessa problemática como modo de garantir retaguarda institucional para as demandas relacionadas à erradicação do trabalho infantil doméstico (OIT, 2011).

Esse trabalho era fundamentado em normativas internacionais acerca dos direitos da criança e do adolescente e sobre o trabalho infantil. Ao mesmo tempo, a atuação de organizações nacionais e internacionais também estimulou mudanças de legislação, como no caso das alterações das determinações do Estatuto da Criança e do Adolescente (ECA) sobre o trabalho infantil e a definição do trabalho infantil doméstico como uma das piores formas de trabalho infantil.

No Pará, a discussão sobre essa temática se iniciou em 2000, quando a Região Metropolitana de Belém, capital do Estado, foi escolhida pela OIT-Ipec (Programa Internacional para a Eliminação do Trabalho Infantil) para ser um dos lugares de realização de um programa-piloto de combate ao TID, que também ocorreu em Belo Horizonte e Recife. A iniciativa foi executada, no Pará, pelo Centro de Defesa da Criança e do Adolescente do Pará (Cedeca-Emáus) e foi chamada de Programa de Enfrentamento ao Trabalho Infantil 
Doméstico (Petid) ${ }^{8}$. A escolha do Cedeca-Emaús como principal parceiro justificava-se pela estratégia dos organismos internacionais (OIT e Unicef) de dar ênfase a organizações locais com histórico de atuação na área de direitos humanos e direitos da criança (Black, 2002).

Havia, portanto, em relação ao TID, um pano de fundo normativo que embasava o engajamento de organizações sociais e governamentais no enfrentamento desse problema. Todavia, dois grandes desafios com os quais o Petid se deparou foi conseguir estimular políticas públicas adequadas e suficientes para a erradicação do TID e lidar com a forte tolerância social a esse tipo de prática. As principais ações de comunicação do Programa foram a realização de campanhas publicitárias e ações de advocacy junto aos media locais, com a finalidade de garantir a cobertura jornalística sobre o assunto. O Petid lançou, entre 2001 e 2007, três campanhas contra o trabalho infantil doméstico 9 . Consta em relatórios do Petid a realização de oficinas com jornalistas sobre o tema e que o combate ao TID "ganhou grande apoio dos meios de comunicação locais" (Cedeca-Emaús, 2002, p. 17). Além disso, as Organizações Rômulo Maiorana (ORM), responsáveis pelo Grupo Liberal (emissora de televisão, jornal impresso e rádios), atuaram convocando outros empresários a se unir pela temática por meio da Câmara Setorial de Responsabilidade Social, da Associação Comercial do Pará ${ }^{10}$.

É possível afirmar que o Petid e seus parceiros realizaram o que Silvio Waisbord (2009) chama de "jornalismo de defesa civil" (ou civic advocacy journalism), ao procurar influenciar o noticiário em prol da cobertura do TID. As organizações da sociedade civil, dependendo do tipo de trabalho que desenvolvem, podem ser ouvidas e consideradas pelos media ainda que não detenham o poder político do Estado ou o poder econômico das grandes

8 Nos primeiros anos, o Petid tinha também o apoio do Unicef e da Save the Children, além de ser apoiado por organizações locais. Nos últimos anos, a principal parceira internacional foi a Cordaid, entidade holandesa que tem entre suas atribuições o cuidado com saúde e educação de crianças em situação de vulnerabilidade.

Nacionalmente, de modo paralelo, organizações como OIT, Unicef, Fundação Abrinq, Ministério Público do Trabalho e Andi criaram campanhas publicitárias com o objetivo de chamar a atenção social para o TID. A Andi foi a principal articuladora nacional entre as fontes relacionadas ao TID e os media, com a divulgação de materiais específicos para subsidiar o trabalho jornalístico, as pesquisas e os encontros de capacitação sobre o tema. Além disso, regionalmente, os projetos de combate ao TID criaram suas próprias campanhas e ações de comunicação, como foi o caso do Petid de Belém.

10 Essa parceria está evidente no convite impresso feito para convocar empresários para um café da manhã sobre oTID, também consta de modo bastante claro nos relatórios do Programa e em matérias jornalísticas publicadas em $O$ Liberal. 
empresas. De acordo com esse autor, os media não são apêndices de governos nem do mercado, "em vez disso, os meios de comunicação devem ser entendidos como arenas nas quais interesses concorrentes procuram obter acesso e influência" (Waisbord, 2010, p. 136; tradução nossa). Desse modo, o jornalismo de defesa civil contribui para trazer à cena midiática assuntos e vozes da sociedade civil. As premissas para a realização desse tipo de ação são baseadas na ideia de que os media possuem um papel fundamental para a realização de transformações sociais e políticas e para a construção de problemas públicos (Waisbord, 2009). Do contrário, "a invisibilidade e deturpação na mídia podem minar os esforços gerais para promover conscientização e políticas públicas" (Waisbord, 2009, p. 9; tradução nossa).

Segundo Rousiley Maia (2012), os processos de discussão social ampliada acerca de injustiças que afetam determinados grupos não precisam ser iniciados necessariamente pelos próprios afetados, pois eles podem não estar em condições de exercer esse papel quando se encontram em situação de exploração e sujeitos a outras vulnerabilidades. "Nesse caso, os críticos sociais, defensores de certas causas, empreendedores morais ou membros de movimentos sociais que têm afinidade ou se identificam com a situação vivida por tais sujeitos podem iniciar o processo de deliberação e de autorreflexão" (Maia, 2012, p. 41-42; tradução nossa). Para a autora, os agentes de advocacy criam e propiciam recursos e oportunidades para a tematização pública do problema em tela. Nesse sentido, "eles podem ser bem-sucedidos em sustentar o debate na esfera pública, incluindo o ambiente dos media" (Maia, 2012 p. 42; tradução e grifos nossos), o que pode contribuir para o questionamento de práticas arraigadas socialmente como o TID.

Entretanto, permanece a tensão acerca da "autoexpressão dos dominados” (Miguel, 2011) em processos políticos de representação mais ampla de meninos e meninas, na qual figuras de autoridade e especialistas tendem a definir o que seria melhor para elas (Miguel, 2011; Earls, 2011). Não se trata simplesmente de defender a ideia de que somente as meninas e mulheres que são ou foram trabalhadoras infantis domésticas podem falar em nome dos interesses delas, mas de pensar quais implicações democráticas a ausência desses sujeitos no debate público pode ocasionar.

Cláudia Fonseca e Andrea Cardarello (1999) analisam como a noção de direitos humanos é traduzida na prática a partir de campanhas de reivindicação de direitos empreendidas por ativistas e organizações em 
nome de sujeitos subalternizados. A questão levantada pelas autoras é pertinente para a discussão que empreendemos neste artigo sobre os limites do advocacy: "que vantagens tiram esses grupos 'subalternos' dessas embalagens mediáticas?” (Fonseca e Cardarello, 1999, p. 85). Elas ressaltam que, apesar das campanhas dos ativistas serem fundamentais para inserir temas sociais na agenda política, essas "frentes discursivas" podem acabar reificando o grupo que deseja defender, pois "correm o risco de montar programas que não apenas deixam de alcançar os seus objetivos, mas, pior que isto, produzem novas formas de exclusão" (idem, ibidem). É verdade que grupos subalternos, sobretudo os pouco organizados politicamente, como os das trabalhadoras infantis domésticas, possuem possibilidades escassas de participação efetiva nas discussões públicas que lhes dizem respeito. Nesse sentido, as ações de advocacy contribuem para manifestar publicamente injustiças vividas por esses sujeitos. Entretanto, o que Fonseca e Cardarello (1999) alertam é que a defesa abstrata de certos direitos, principalmente a partir de uma perspectiva externa aos concernidos, pode obscurecer práticas e percepções desses sujeitos. Ou, nas palavras das autoras, deve-se evitar "misturar os nomes que nós inventamos com a realidade que os outros vivenciam" ( $\mathrm{p}$. 118). Portanto, a questão que perseguimos neste artigo não se resume à defesa da simples expressão das meninas e mulheres vitimizadas pelo TID. Em vez disso, busca-se compreender, a partir de um caso de advocacy, quais as implicações democráticas desse tipo de atuação política na cena pública.

Para possibilitar a reflexão sobre esse assunto, soma-se às perspectivas teóricas já apresentadas a discussão de Flávia Biroli (2013) sobre as possibilidades de agência das mulheres. Essa autora aponta que há constrangimentos sistemáticos que repercutem de maneira desigual e diferenciada na forma como os sujeitos se posicionam no mundo. É o que ela chama de "agência desigualmente imperfeita". Essa perspectiva, ao mesmo tempo que permite a consideração sobre a maneira pela qual "as desigualdades incidem sobre as condições sociais em que as preferências são produzidas”, entende que os impedimentos à autodeterminação "têm impacto diferenciado segundo o pertencimento dos indivíduos a grupos sociais: organizam-se estruturalmente e incidem de maneira diferenciada segundo a posição social dos indivíduos" (Biroli, 2013, p. 54). 
Com base nesse contexto, é possível questionar: considerando as profundas desigualdades ligadas ao TID e as tensões relacionadas à expressão dos sujeitos envolvidos, quais são as reverberações democráticas das ações de advocacy na luta desencadeada publicamente contra o TID?

\section{Procedimentos metodológicos}

Com o objetivo de refletir sobre a atuação pública, sobretudo midiática, do grupo de advocacy contra o TID, optamos por realizar a análise da cobertura dos dois principais jornais locais (O Liberal e Diário do Pará) ${ }^{11}$, de 2000 a 2009, período de atuação do Petid em Belém, o que representou 136 textos $^{12}$. Esse contexto comunicativo, embora influenciado pelas ações de civic journalism advocacy do Petid, é marcado pelas rotinas produtivas do jornalismo. Entendemos os media a partir da perspectiva sistêmica defendida por Rousiley Maia (2012), segundo a qual os media possuem uma complexidade constituinte porque, ao mesmo tempo que são permeados por ações e motivações estratégicas, podem ser também ambiente para a busca da cooperação comunicativa e da discussão de cidadãos acerca de questões sociais.

Em relação à distribuição por jornal, houve mais publicações sobre trabalho infantil doméstico em O Liberal (64,7\%) do que no Diário do Pará $(35,3 \%)$. Consideramos que o principal fator a estimular essa diferença significativa foi a parceria firmada entre o Petid e O Liberal, de tal forma que grande parte dos eventos relativos ao TID eram cobertos pelo jornal, além

\footnotetext{
1 Ambos os jornais possuem uma abrangência regional, embora tenham distribuição nacional. O Liberal é mais antigo - remonta ao ano de 1940 -, porém está sob o comando da família Maiorana, que o administra desde 1966. Passou por um grande processo de modernização e havia se tornado liderança absoluta no jornalismo diário paraense, razão pela qual exercia forte influência na sociedade e nas elites paraenses (Veloso, 2008). O jornal faz parte das Organizações Rômulo Maiorana, conglomerado de empresas, do qual constam, na área de comunicação, outro jornal, emissoras de rádio e uma de televisão (filiada à Rede Globo), televisão a cabo e um portal de notícias na internet, entre outras. O Diário do Pará foi criado em 1982 pela família do ex-governador do Pará e atual senador Jader Barbalho (PMDB). Faz parte também de um conglomerado midiático que reúne portal de notícias na internet, emissoras de rádio e uma de televisão (filiada à Rede Bandeirantes). Nos anos de 2000, o Diário do Pará conseguiu alcançar a liderança de O Liberal, segundo pesquisa do Ibope (Veloso, 2008). O cenário atual é de forte disputa empresarial e jornalística entre os dois veículos.

12 Os materiais empíricos apresentados neste trabalho correspondem a um recorte do banco de dados que serviu de base para a construção das nossas pesquisas de mestrado e doutorado (realizadas entre 2005 e 2014). Além de matérias dos media paraenses, referentes ao período de janeiro de 2000 a dezembro de 2009, e das peças publicitárias do Petid, temos ainda grupos focais realizados com dois públicos específicos: patroas e trabalhadoras infantis domésticas, que, em razão do escopo, não serão utilizados neste artigo.
} 
da publicação de matérias especiais, sobretudo na página de Responsabilidade Social que circulava no caderno de Política todas as quintas-feiras. Em relação à divisão por editorias, a cobertura acerca do TID se concentrou, principalmente, no caderno Atualidades $(54,4 \%)$, seguido pelo de Polícia $(19,1 \%)$ e pelo de Política (13,2\%).

Houve pouca diferença entre o percentual de notícias e reportagens (Tabela 1), provavelmente em razão de termos excluído do nosso corpus matérias que tratavam apenas pontualmente do TID. Mantivemos somente as notícias que abordavam esse tipo de trabalho infantil ou um de seus aspectos de modo relativamente significativo, ou seja, quando o tema em si ou parte dele eram minimamente colocados e discutidos no texto. Excluímos as matérias que apenas citavam esse tipo de trabalho infantil.

Tabela 1 - Distribuição de matérias por gênero jornalístico (O Liberal, 2000-2009)

\begin{tabular}{c|c|c}
\hline gênero & qtd & $\%$ \\
\hline notícia & 69 & 50,7 \\
\hline reportagem & 63 & 46,3 \\
\hline editorial & 2 & 1,5 \\
\hline entrevista & 2 & 1,5 \\
\hline total & 136 & 100,0 \\
\hline
\end{tabular}

Fonte: Elaboração própria.

No período estudado, encontramos ainda dois editoriais de $\mathrm{O}$ Liberal acerca do assunto e duas entrevistas de página inteira que tratavam da temática: uma com a advogada Celina Hamoy, coordenadora do Cedeca-Emaús, e outra com Roberta Sandrelli, patroa então acusada de assassinar uma menina de onze anos que trabalhava como babá em sua casa.

A trajetória de crescimento da quantidade de matérias jornalísticas acerca do TID no Pará acompanha o desenvolvimento do Petid e o início da tematização pública desse tipo de trabalho infantil, principalmente devido à divulgação dos resultados de pesquisas locais e nacionais sobre o assunto, como se pode ver no Gráfico 1. A forte subida em 2002, e mantida em 2003, representa os anos de atuação mais consolidada do Programa e o início do financiamento da OIT ao projeto paraense. Nesse período, foram realizadas ainda pela Andi - Comu- 
nicação e Direitos, juntamente com o Cedeca-Emaús, oficinas com jornalistas acerca do tema trabalho infantil doméstico. Em 2004, a subida se acentua quando é lançada a segunda fase da campanha de publicidade do Petid. Em novembro de 2005, ocorreu a morte da menina Marielma de Jesus Sampaio, de onze anos, assassinada pelos patrões que a levaram de Vigia, cidade do interior do Pará, com a finalidade de se tornar babá da filha deles em Belém. O caso e os respectivos desdobramentos legais ganharam bastante repercussão entre os anos de 2006 e $2007^{13}$. De 2008 a 2009, percebemos uma queda na quantidade de matérias sobre o assunto, porém, nesse período, houve um número significativo de reportagens que discutiam diferentes nuances do TID.

Gráfico 1 - Variação da cobertura sobre TID por quantidade de matérias no período estudado

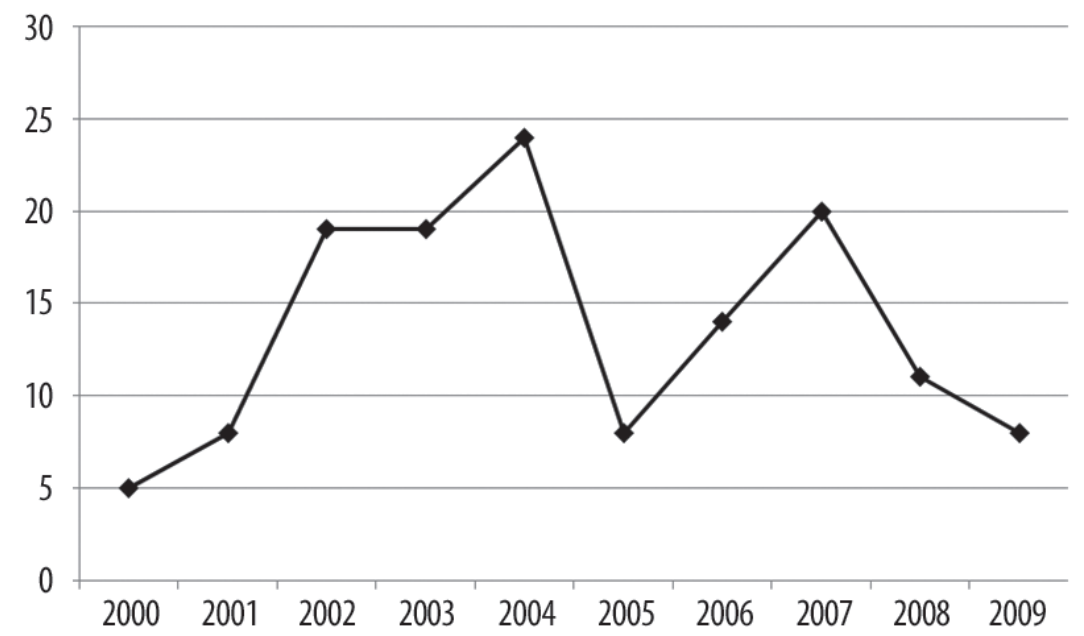

Fonte: Elaboração própria.

Observamos em outros momentos (Cal, 2007; Maia e Cal, 2014) que, de modo geral, a cobertura acompanhou os enquadramentos preferenciais do Petid e parceiros, ou seja, o modo como o TID foi abordado nos jornais estudados correspondeu aos discursos que vinham sendo construídos pelos agentes

13 É relevante destacar que, para a composição de nosso corpus, consideramos apenas as matérias sobre o caso que problematizaram algum aspecto do trabalho infantil e não que somente noticiavam os fatos relativos ao crime ou ao julgamento dos acusados. 
de advocacy. Destacam-se os seguintes enquadramentos: (1) a invisibilidade do trabalho infantil doméstico e (2) as injustiças relacionadas a essa prática. O primeiro enquadramento dizia respeito ao modo naturalizado pelo qual o TID é considerado pela sociedade, aos desafios da tematização pública por se realizar em ambiente íntimo dos lares e a aspectos de gênero que fazem com que essa prática não seja questionada. O segundo diz respeito às injustiças do TID e engloba discursos que o consideram o uma forma de exploração de crianças e adolescentes, uma violação de direitos e uma "falsa" caridade. De modo geral, os media estudados ressaltaram os aspectos negativos relacionados ao TID do ponto de vista dos direitos da infância e da adolescência e concederam espaços de fala principalmente para os agentes e parceiros do Petid.

Neste artigo, analisaremos os materiais jornalísticos com base em três categorias principais identificadas a partir da relação entre referencial teórico e corpus empírico: (1) a natureza das desigualdades relacionadas ao TID, ou seja, quais os tipos de desigualdades tematizados na cobertura jornalística sobre o assunto; (2) os lugares de fala e os posicionamentos de meninas e mulheres envolvidas com o TID, portanto, qual é o lugar atribuído a esses sujeitos na cena midiática; e, por fim, (3) a relação apresentada nos jornais entre os agentes de advocacy e as afetadas.

Como referencial metodológico, inspiramo-nos na análise crítica do discurso, segundo a qual analisar discursos também significa analisar práticas na medida em que é por meio dos primeiros que as últimas ganham sentido e expressão. De acordo com Norman Fairclough, Jane Mulderring e Ruth Wodak (2011), esse ponto de vista sugere uma relação dialética entre discursos e o contexto social que os enquadra. Trata-se, portanto, de uma relação em dois sentidos: "o evento discursivo é conformado pelas situações, instituições e estruturas sociais, mas também os conforma” (Fairclough, Muldering e Wodak, 2011, p. 357; tradução nossa). Assim, o foco nas práticas sociais permite, de acordo com Fairclough (2013), articular a perspectiva das estruturas, ou dos contextos mais amplos que sustentam padrões opressivos, com as possibilidades de ação e de transformação social.

\section{A natureza das desigualdades relacionadas ao TID}

De acordo com Luis Felipe Miguel (2014), desigualdades referem-se a assimetrias relativas ao controle de certos recursos. $\mathrm{O}$ autor compreende desigualdade a partir de três eixos principais: 
[...] (1) possui impacto nas trajetórias possíveis relativas de indivíduos e grupos; (2) reflete padrões estruturais, não sendo efeito do acaso ou de escolhas pessoais livres; (3) está vinculada a relações de dominação, isto é, à capacidade de uns bloquearem a ação autônoma e/ou obtenção de ganhos por parte de outros (Miguel, 2014, p. 300).

Nesta seção, importa-nos analisar como o trabalho infantil doméstico foi tematizado nos jornais investigados e qual a natureza das desigualdades a ele relacionadas pelos discursos dos media e pelos agentes sociais que advogam contra essa prática. Nos textos jornalísticos analisados, o TID foi definido como uma atividade em que prepondera uma relação de dominação latente, que suaviza processos de dominação e faz com que não sejam percebidos por suas maiores vítimas. Assim, os jornais atuaram no sentido de desvelar componentes ideológicos que sustentariam o TID, destacando como falsas as promessas que incentivam a saída de crianças para casas de família, como exemplifica o trecho a seguir:

Lavar, passar, cozinhar, varrer a casa e cuidar de crianças. Se para adultos essas tarefas já são um grande esforço físico, para as crianças representam desgaste dobrado. O trabalho infantil doméstico (TID) é um crime que, maquiado pela oferta de "ajuda" a quem não tem oportunidades, contraditoriamente nega às vítimas o direito de brincar, estudar e escolher uma profissão $(O$ Liberal, 12 fev. 2004).

O sentido de desigualdade que ganhou destaque na cobertura, portanto, refere-se à terceira definição apontada por Miguel (2014), segundo a qual podemos compreender desigualdade como a capacidade de uns impedirem a agência autônoma de outros mediante relações de poder.

As desigualdades sociais também foram abordadas na cobertura jornalística sobre o tema, principalmente relacionadas à pobreza e à educação. Esse tipo de desigualdade é aquele que "reflete padrões estruturais" independentemente da escolha dos indivíduos (Miguel, 2014, p. 300). A aprendizagem formal foi apontada como a área mais prejudicada pelo TID em razão das longas jornadas de trabalho e da reprodução da pobreza, na medida em que o fracasso na escola diminui as oportunidades que crianças e adolescentes teriam de obter sucesso profissional em outras atividades. 
F.R. começou a trabalhar como babá aos 10 anos. A partir das dicas de uma amiga, a menina foi cuidar de uma criança de dois anos durante três dias na semana. [...] No início, por R\$ 50 [mensais] ${ }^{14}$, a menina deveria "reparar" o bebê. Após duas semanas, sua patroa passou a exigir trabalho diário. A menina parou de estudar e virou empregada doméstica: lavava, passava, limpava a casa. $\mathrm{O}$ trabalho consumia todo o seu dia (O Liberal, 5 mar. 2002).

Os sentidos atribuídos ao trabalho infantil pelos media estudados se relacionam à violação de direitos, à exploração de meninas e à escravidão. Contudo, nessa cena pública construída em torno do TID, não há referência a conflitos. Como os processos de dominação são considerados internalizados, o que ganha relevância são a resignação e a aceitação desse tipo de trabalho.

Dona Raimunda Alcântara Lima, mãe de Paula Fernanda, de 17 anos, já amargou a experiência de ter uma filha no trabalho doméstico. Aos 16 anos, Dora, hoje adulta, mudou-se para Belém, para empregar-se na casa de conhecidos. "Prometeram estudo e tudo que ela precisasse. Não prometeram salário. Como aqui [em Soure/Marajó] não tem emprego, ela se empolgou, mas passou só três meses. Ela trabalhava como uma escrava, dava até banho em porco", relembra a senhora (O Liberal, 9 mar. 2003; grifos nossos).

O TID é apresentando como uma alternativa diante das condições estruturais que limitam as possibilidades de escolha e ação de adolescentes de municípios distantes da capital (“Como aqui não tem emprego"). Entretanto, apresenta o risco de colocar essas meninas em uma grave situação de vulnerabilidade. A sujeição das adolescentes à dominação no TID é referida em analogia ao trabalho escravo. Poucas vezes, durante os dez anos de matérias investigadas, as próprias afetadas utilizaram essa referência. Esse discurso estava presente, sobretudo, na fala de especialistas e de agentes sociais, além de aparecer expresso nos títulos, subtítulos e em outros recursos de edição dos jornais. Segundo a mãe de uma ex-trabalhadora infantil doméstica, não era o fato de não receber salário que caracterizava o TID como escravidão, mas sim ela ter que realizar todo tipo de serviço. Mesmo sem a promessa de salário, a menina seguiu para o trabalho doméstico em troca de benesses. De modo recorrente, as pessoas afetadas citam nas matérias que os patrões

14 O salário mínimo naquela época era de $\mathrm{R} \$ 200,00$. 
prometeram dar "tudo que a menina precisasse"; no entanto, há grande descompasso entre o que a menina e a sua família consideram o "necessário" e o que as famílias empregadoras pensam acerca disso. É pertinente destacar que o terreno político e social que marca essas desigualdades poucas vezes é questionado na cena pública, apesar da atuação de grupos de advocacy voltados a tematizar as injustiças vivenciadas por sujeitos subalternos (Maia, 2012).

Em uma entrevista de página inteira no jornal Diário do Pará, a advogada Celina Hamoy, coordenadora do Cedeca-Emaús, é questionada sobre violência e direitos da criança e do adolescente. Um dos focos da entrevista foi o trabalho infantil doméstico. Ao ser indagada se esse tipo de trabalho infantil podia ser considerado uma violência, ela responde:

É com certeza uma violência. [...] E a violação acontece principalmente pelo imaginário que existe na sociedade: "Não, ela não está trabalhando, eu tô ajudando, isso é tão comum”. Aí a menina começa a chamar a patroa de tia, de madrinha, começa a haver aquela troca: "Tu me dá trabalho, eu te dou roupa". Nada mais é e chega a caracterizar o trabalho escravo mesmo (Diário do Pará, 27 abr. 2008).

Assim, a violência do TID não é caracterizada por suas formas explícitas, mas reside no fato de existirem consensos sociais que tornam o TID aceito e tolerado socialmente. Os discursos dos jornais e dos atores sociais chamados a se pronunciar nesse espaço de visibilidade ressaltam, portanto, as desvantagens que a prática do TID pode acarretar para meninas envolvidas, ainda que aparentemente, ou melhor, socialmente, seja considerado como uma relação de ajuda mútua, na qual a ambiguidade entre ser ou não da família incentiva o não pagamento de salário. Por esses motivos, a representante do Cedeca-Emaús o caracteriza como trabalho escravo. Ela afirma que existe uma tolerância social dessa prática, o que dificulta a percepção do TID como um problema. A grande diferença entre o valor merecido pela atividade realizada pelas adolescentes e o que elas efetivamente recebem como pagamento também é criticada.

De modo geral, na cobertura, o TID é considerado como aquilo que causa/aprofunda desigualdades principalmente por prejudicar o processo de aprendizado formal das meninas envolvidas. Esse discurso é sustentado sobretudo pelos agentes de advocacy e especialistas consultados pelos jornais. De certo modo, esse achado remete-nos à ponderação de Fonseca e 
Cardarello (1999) sobre a ideia de que a defesa abstrata de alguns direitos - o da educação formal, por exemplo - pode ocultar práticas e, no caso, desigualdades vivenciadas por esses sujeitos. O enfoque midiático genérico nessa perspectiva não fomenta uma discussão mais estrutural sobre as desigualdades que fazem com que esse tipo de trabalho infantil seja tão amplamente considerado uma escolha efetivamente possível (até desejável) para meninas pobres.

\section{Lugares de fala de meninas e mulheres trabalhadoras}

Os discursos contrários ao trabalho infantil doméstico e sobre o que seriam os melhores interesses das crianças e adolescentes envolvidas foram majoritariamente apresentados e sustentados nos media investigados por atores sociais e especialistas (o que correspondeu a 50\% das fontes ouvidas). Os agentes de advocacy atuaram como representantes autoautorizados das afetadas pelo TID. De acordo com Nadia Urbinati e Mark Warren (2008), nesse tipo de representação não há necessidade da autorização prévia dos concernidos ${ }^{1515}$. Organizações e atores sociais atuam "em nome de interesses e valores que acreditam devem ter um impacto" (Urbinati e Warren, 2008, p. 403). Assim, o interesse em questão é a erradicação do TID e, em prol dessa causa, agentes de advocacy atuam representando as meninas envolvidas nessa prática, buscando não apenas influenciar políticas governamentais, mas principalmente a cultura e os discursos sobre esse tipo de trabalho.

Trabalhadoras (e ex-trabalhadoras) infantis domésticas também tiveram voz na cena midiática, ainda em um número bem menor de ocorrências $(16,4 \%)$; porém o lugar de fala atribuído a elas era fincado particularmente no relato de situações opressivas e desrespeitos vividos no exercício do TID. Assim, apesar de terem espaço de fala, o modo como os jornais construíram esse lugar, em vez de proporcionar um discurso "libertador" - nos moldes mencionados por Linda Alcoff (1991) e Gayatri Spivak (2010) -, capaz de romper com a posição subalterna ou de opressão, acabou por reforçar, em alguma medida, esse lugar subalterno, porque as falas críticas ao TID ou

\footnotetext{
Os autores argumentam que a representação autoautorizada tem crescido muito nos últimos anos. Trata-se de um fenômeno multifacetado em que o objeto/sujeito representado pode variar entre temas (direitos humanos, educação, meio ambiente), grupos (como mulheres, crianças, marginalizados etc.) ou mesmo discursos, ao defender determinadas posições ou argumentos. Portanto, esse tipo de representação implica desafios em relação aos modos de autorização e aos processos de accountability que deveriam sustentá-lo (Urbinati e Warren, 2008).
} 
mesmo de superação eram permitidas, essencialmente, a quem participava de programas sociais (Petid, sobretudo). Portanto, as vozes de destaque no enfrentamento ao TID na arena midiática foram daqueles que falavam em nome das meninas e mulheres envolvidas.

Um dos maiores dramas do trabalho infantil doméstico é que ele deixa marcas que a sociedade não enxerga, mas que são profundas e carregadas durante anos pelas meninas que um dia passaram por isso. Muitas delas relatam com uma triste naturalidade passagens em que foram ameaçadas ou maltratadas por patroas e não raramente se mostram resignadas com a situação de extremo desrespeito e violência. "Uma vez, ela [a patroa] ameaçou me jogar embaixo de um carro se eu não cuidasse direito do filho dela", disse Marlene do Socorro Teixeira da Silva, hoje com 18 anos.

[...]

A mãe [de Marlene], dona Argentina, já falecida, engravidou do filho do patrão situação muito comum, já que não são raros casos em que filhos e maridos de patroas se aproveitam sexualmente de adolescentes (O Liberal, 10 maio 2007; grifos nossos).

Marlene tinha quatorze anos quando começou a trabalhar nessa casa. O lugar de fala imposto a ela pelo discurso jornalístico é marcado por expressões relacionadas à aceitação da dominação, como a indicação de que as situações de violência são relatadas com "uma triste naturalidade" e a partir de uma postura de resignação, de tal modo que a ameaça ou a violência são entendidas como características (ou riscos corriqueiros) do TID. Não há menção a possibilidades de crítica ou de questionamento dessa realidade pela própria personagem vitimizada pelo TID. O texto mobiliza um entendimento do TID como baseado em uma relação de poder que chega ao limite da violência contra o outro, das ameaças, e que é tratada com naturalidade de tão comuns que são. Nesse contexto, parece não haver alternativa senão a total sujeição aos mandos e desmandos dos patrões. Assim, o direcionamento da matéria enclausura a personagem no papel de vítima e o modo como faz isso impossibilita o vislumbre de uma transformação nesse cenário ou na posição que a adolescente trabalhadora doméstica ocupa no mundo.

Embora crianças e adolescentes afetadas tenham tido voz no noticiário acerca da conceituação do trabalho infantil doméstico, o que em princípio demonstraria a possibilidade de "autoexpressão dos dominados" (Miguel, 2011), uma vez que não são somente especialistas e representantes de organizações sociais que estavam falando por elas nos media, o modo pelo qual 
esse lugar de fala é construído reforça a necessidade de tutela desses sujeitos, já que só lhes é permitido esse discurso de superação quando participam de projetos ou programas sociais que lhes deem suporte. Ou seja, as conquistas relativas ao reconhecimento da própria condição e ao empoderamento desses sujeitos para que busquem outra realidade estão atreladas, no entanto, à dependência das organizações de enfrentamento ao TID.

Esse caso traz um problema à discussão sobre o "falar em nome de outros", (Alcoff, 1991; Urbinati e Warren,2008). Para Linda Alcoff (1991, p. 9), ao falar pelos outros ou falar sobre os outros, estamos representando "as necessidades, os objetivos, a situação dos outros e, na verdade, quem eles são", o que, segundo a autora, atua na construção do lugar que esses outros por quem se fala ocupam no mundo. Portanto, falar por outro implica participar da construção de lugares e papéis sociais que são atribuídos a esse outro. E, no caso estudado, isso significou reforçar o lugar de subalternidade das trabalhadoras e ex-trabalhadoras infantis domésticas, além de desconsiderar posições e propostas desses sujeitos para o enfrentamento do TID.

\section{Agentes de advocacy e as trabalhadoras}

A partir do contexto apresentado na seção anterior, parece não haver resistência: a sujeição da menina trabalhadora é a regra. Contudo, há uma quebra nesse cenário com a introdução das ações de organizações sociais pelo enfrentamento ao TID, sobretudo o Cedeca-Emaús por meio do Petid. Quando meninas atendidas pelo Programa ganham espaço nos jornais, constrói-se um discurso acerca da resistência delas ao TID com a ajuda decisiva do Petid. Por essa razão, expressões como "A vida delas mudou quando conheceram o Centro de Defesa da Criança e do Adolescente (Cedeca)" destacam essa lógica discursiva:

A menina, que não teve tempo para brincar por conta do trabalho de babá, hoje está com a autoestima resgatada e sonha em fazer Administração. "A vida mudou bastante. Do jeito que era... Está muito melhor agora”, comemora Thayslane, de 16 anos. Thays está estagiando na Agência do Basa [...]. Thays faz parte de uma triste estatística de crianças que partem para o serviço doméstico, sob o incentivo da família, para complementar a renda da casa. [...]. Por isso, a irmã de Thays, Thayana da Silva Lima, também arrumou o subemprego de babá na vizinhança. 
A vida delas mudou quando conheceram o Centro de Defesa da Criança e do Adolescente (Cedeca) [...]. A família conseguiu uma bolsa-escola, Thays fez um curso de computação na República de Emaús e conseguiu um estágio de 18 meses, iniciado em dezembro do ano passado. Hoje, a casa da família, que era de madeira e estava bastante deteriorada, está sendo substituída por uma de alvenaria (O Liberal, 18 mar. 2004; grifo nosso).

O Petid é apresentado, então, como aquele que afiança um futuro para adolescentes envolvidas no TID. Assim, as personagens das matérias parecem só "ter futuro" se forem atendidas por programas e projetos sociais. Entretanto, não há matérias com questionamentos sobre a eficácia do Petid ao lhes garantir isso. Um dos tensionamentos apontados por Miguel (2014) sobre as ações de advocacy é o de que essa forma de representação não estimularia a atuação autônoma tanto coletiva como individualmente dos sujeitos aos quais se busca representar. Os discursos dos media sobre a relação entre o Petid e as meninas trabalhadoras buscaram mostrar o quanto a inserção nesse programa possibilitou o exercício de autonomia por parte desses sujeitos: da autonomia individual a partir da definição de metas e projetos de futuro; e da coletiva a partir do engajamento político no enfrentamento ao trabalho infantil. As meninas entrevistadas e/ou cujas histórias de superação são apresentadas nas matérias não possuem espaço para lançar um olhar crítico para o próprio Petid, e, como vimos, o lugar de fala das que não possuem relação com o Programa é marcado pela vitimização. Assim, essa possível autonomia conquistada a partir da inserção do Programa e defendida nos discursos dos media analisados permanece sob suspeita.

Nesse sentido, o fato de os media analisados terem abordado o trabalho infantil doméstico prioritariamente do ponto de vista de organizações e atores sociais, inclusive como parceiro formal no caso de $O$ Liberal, não estimulou uma postura crítica em relação ao modo como o Petid estava sendo desenvolvido e sobre o impacto concreto na vida das atendidas, mesmo as que já haviam sido beneficiadas não estavam mais vinculadas a ele. As ações de jornalismo de defesa civil desdobraram-se, portanto, não apenas na inclusão do TID na pauta jornalística, mas também representaram uma limitação dessa cobertura que esbarrava na impossibilidade de distanciamento para lançar um olhar crítico às ações do Petid e parceiros. 


\section{Considerações finais}

O estudo empreendido sobre o trabalho infantil doméstico (TID) expõe aspectos da contradição apontada por Biroli (2013) entre os valores e as práticas democráticas e a tolerância social às relações de subordinação. $\mathrm{O}$ principal deles, a nosso ver, refere-se ao lugar atribuído às meninas e mulheres concernidas na vida privada e social - hierarquicamente desvalorizado em razão da articulação de posições de gênero e de classe - e na luta, na cena pública, contra esse tipo de trabalho.

A partir do caso do TID, podemos relacionar três limitações fundamentais do processo de advocacy investigado. A primeira diz respeito ao confinamento do lugar de fala dos sujeitos a quem se busca representar, o que repercute na ausência de posicionamento público deles como sujeitos políticos e na exclusão, na arena midiática, de temas e posições vindas de quem exerce ou exerceu o trabalho infantil. A segunda refere-se ao não aprofundamento da problematização sobre o contexto de desigualdades que leva meninas ao trabalho doméstico. Por fim, a terceira corresponde ao fato de os agentes de advocacy não terem sido capazes de tematizar publicamente o trabalho doméstico realizado por meninas na própria casa. Esta última situação encontra-se envolta num certo dever das adolescentes com a família, como se fosse natural que cuidassem da casa ou dos irmãos no lugar de um adulto. Desenvolver esse tipo de atividade pode ser tão opressor e violar direitos quanto o trabalho na casa de terceiros.

Assim, se, como afirma Maia (2012), por um lado, agentes de advocacy são fundamentais para tematizar injustiças, por outro corre-se o risco, como alerta Miguel (2011), de não se atribuir a atenção devida à autoexpressão dos representados. No caso em análise, meninas e mulheres que vivenciaram o TID foram posicionadas na cobertura jornalística, de modo geral, como sujeitos a quem era permitida a expressão da dor e do sofrimento infligidos pelo TID. É necessário reconhecer o potencial político desse tipo de relato, capaz de descortinar situações por vezes desconhecidas ou não reconhecidas como violações de direitos pela sociedade. Entretanto, no caso investigado, esses relatos, de certa forma, contribuíram para manter a distância e, nesse sentido, aprofundar as desigualdades entre quem sofre e quem assiste/lê. Permanece, assim, o contexto de sujeição que é contraposto apenas quando há menção direta à interferência do Petid e dos agentes de advocacy.

Além disso, uma abertura mais significativa aos posicionamentos dessas meninas e mulheres poderia significar um questionamento mais amplo das 
desigualdades que ocasionam o TID, mas que não foram tematizadas, como os constrangimentos estruturais que fazem esse tipo de situação apresentar-se como a "melhor alternativa possível" para meninas pobres, ou ainda os padrões de reprodução da dependência socialmente produzida. Sobre isso, Biroli (2013, p. 192) afirma que dependência e cuidado consistem "em questões políticas, a despeito da recusa frequente a tematizá-las. Têm grande efeito na socialização dos indivíduos e, ainda que se definam como arranjos privados, desdobram-se em desigualdades e na vulnerabilidade relativa de alguns". Tais temáticas são fundamentais na discussão sobre o TID. Por não existir uma discussão consistente politicamente sobre a "responsabilidade compartilhada pela dependência incontornável" (Biroli, 2013, p. 200), essa responsabilidade é repassada, muitas vezes, a meninas a quem cabe os cuidados com os irmãos mais novos ou ainda com os filhos dos patrões. Mesmo empregadas domésticas adultas precisam de pessoas que cuidem de seus filhos enquanto vão trabalhar e frequentemente recorrem a meninas parentes ou vizinhas. Essa é uma das principais feições contemporâneas do TID.

Sobre a relação entre os agentes do Petid e os jornais locais, apesar de ser bastante produtiva do ponto de vista social a adoção das perspectivas dos agentes sociais pelos media, ao permitir a tematização de injustiças, avaliamos que ocorreu uma "aderência acrítica" aos discursos e posicionamentos dos agentes de advocacy, de forma que não houve espaço para a avaliação das possibilidades concretas de mudança na vida das adolescentes provocadas por ações do Petid. A iniciativa em si não foi objeto de avaliação.

Em suma, as ações de advocacy foram essenciais para que o TID fosse discutido publicamente como um problema político. Entretanto, mesmo contando com o apoio dos media locais, a luta pública empreendida pelos agentes de advocacy contra o TID não avançou para a discussão acerca das "condições efetivas para o exercício da autonomia como autodeterminação" (Biroli, 2013, p. 199), das trabalhadoras infantis domésticas.

\section{Bibliografia}

ALBERTO, Maria de Fátima et al. (2009). "Trabalho infantil doméstico: perfil bio-sócio-econômico e configuração da atividade no município de João Pessoa, PB". Cadernos de Psicologia Social do Trabalho, v. 12, n. 1, p. 57-73. Disponível em: <http://www.revistas.usp.br/cpst/article/ view/25775>. Acessado em 25 fev. 2013. 
ALCOFF, Linda (1991). “The problem of speaking for others”. Cultural Critique, n. 20, p. 5-32. Disponível em: <http://www.jstor.org/stable/1354221>. Acessado em 25 fev. 2013.

ARAGÃO-LAGERGREN, Aida (2003). "Urban informal sector. The case of child domestic work in Guatamala city". Revista da Faculdade de Letras, v. XIX, n. 1, p. 99-109.

BIROLI, Flávia (2013). Autonomia e desigualdades de gênero: contribuições do feminismo para a crítica democrática. Vinhedo (SP): Horizonte.

BLACK, Maggie (2002). A handbook on advocacy: child domestic workers finding a voice. Horsham (UK): Printed Word, Anti-Slavery International. BLAGBROUGH, Jonathan (2008). "Child domestic labor: a modern form of slavery”. Children \& Society, n. 22, p. 179-90. Disponível em: <http://onlinelibrary.wiley.com/doi/10.1111/j.1099-0860.2008.00149.x/abstract $>$. Acessado em 10 jan. 2010.

CAL, Danila (2007). Entre o privado e o público: contextos comunicativos, deliberação e trabalho infantil doméstico. Dissertação (mestrado) em Comunicação Social. Belo Horizonte: Universidade Federal de Minas Gerais.

(2014). Configuração política e relações de poder no trabalho infantil doméstico: tensões nos discursos dos media e de trabalhadoras. Tese (doutorado) em Comunicação Social. Belo Horizonte: Universidade Federal de Minas Gerais.

CARNEIRO, Maria Teresa \& ROCHA, Emerson (2009). "Do fundo do buraco: o drama social das empregadas domésticas", em SOUZA, J. A ralé brasileira: quem é e como vive. Belo Horizonte: Editora UFMG.

CEDECA-EMAÚS - Centro de Defesa da Criança e do Adolescente do Pará (2002). Reflexões para o enfrentamento do trabalho infantil doméstico de crianças e adolescentes, promoção e garantia de seus direitos. Belém: Cedeca-Emaús.

EARLS, Felton (2011). “Children: from rights of citizenship”, em KANISS, P. (ed.). The Annals of the American Academy of Political and Social Science. Los Angeles: Sage.

FAIRCLOUGH, Norman (2013). "Critical discourse analysis and critical policy studies”. Critical Policy Studies, v. 7, n. 2, p. 177-97. Disponível em: <http://dx.doi.org/10.1080/19460171.2013.798239>. Acessado em 15 mar. 2014. 
FAIRCLOUGH, Norman; MULDERING, Jane \& WODAK, Ruth (2011). "Critical discourse analysis", em VAN DIJK, T. (ed.). Discourse studies: a multidisciplinary introduction. London: Sage.

FONSECA, Cláudia (1995). Caminhos da adoção. São Paulo: Cortez.

FONSECA, Cláudia \& CARDARELLO, Andrea (1999). "Direitos dos mais e menos humanos”. Horizontes Antropológicos, v. 5, n. 10, p. 83-122.

HASAN, Rukhsana \& SALEEM, Sehrish (2013). “The forgotten children: an exploratory research". Journal of Asian Development Studies, v. 2, n. 1, p. 36-46. Disponível em: <http://globalcentre.org/upload/3.pdf > . Acessado em: 10 mar. 2014

HOYOS, Soraya (2000). "Quién la mandó a ser niña? El trabajo infantil doméstico desde una perspectiva de género”, em VARGAS, G. A.; GARCÍA MÉNDEZ, E. \& HOYOS, S. (eds.). Trabajo infantil doméstico: y quién la mandó a ser niña?. Bogotá: TM Editores, Unicef.

JACQUEMIN, Mélanie (2006). "Can the language of rights get hold of the complex realities of child domestic work? The case of young domestic workers in Abidjan, Ivory Coast”. Childhood, v. 13, n. 3, p. 389-406. Disponível em: <http://chd.sagepub.com/content/13/3/389.abstract>. Acessado em 10 abr. 2010.

JAMES, Alisson (2011). "To be (come) or not to be (come): understanding children's citizenship", em KANISS, P. (ed.). The Annals of the American Academy of Political and Social Science. Los Angeles: Sage.

LAMARÃO, Maria L. N. (2008). A constituição das relações sociais de poder no trabalho infanto-juvenil doméstico: estudo sobre estigma e subalternidade. Dissertação (mestrado) em Serviço Social. Belém: Universidade Federal do Pará.

LAMARÃO, Maria L. N.; MENEZES, Stela M. L. \& FERREIRA, Wanderléa B. (2000). O trabalho doméstico de meninas em Belém. Belém: Cedeca-Emaús.

LIBARDONI, Marlene (2000). "Fundamentos teóricos e visão estratégica da advocacy”. Revista Estudos Feministas, v. 8, n. 2, p. 207-21.

MAFRA, Rennan (2014). "Comunicação, ocupação, representação: três olhares sobre a noção de advocacy em contextos de deliberação pública”. Compolítica, v. 4, n. 1, p. 181-204. Disponível em: <http://compolitica. org/revista/index.php/revista/issue/view/7/showToc $>$. Acessado em 15 mar. 2015. 
MAIA, Rousiley (2011). "Em busca do interesse público: tensões entre a argumentação e a barganha”, em KUNSCH, M. M. K. (org.). Comunicação pública, sociedade e cidadania. São Caetano do Sul: Difusão.

(2012). Media, deliberation and political talk. New York: Hampton Press.

(2014). Recognition and the media. London: Palgrave MacMillan.

MAIA, Rousiley \& CAL, Danila (2014). "Recognition and ideology: assessing justice and injustice in the case of child domestic labor". Journal of Political Power, v. 7, n. 1, p. 63-85. Disponível em: <http://www.tandfonline. com/doi/abs/10.1080/2158379X.2014.887543>. Acessado em 2 abr. 2014. MARCÍlIO, Maria Luiza (2003). "A roda dos expostos e a criança abandonada na história do Brasil”, em FREITAS, M. C. (org.). História social da infância no Brasil. São Paulo: Cortez.

MARQUES, Ângela (2008). “Os meios de comunicação na esfera pública: novas perspectivas para as articulações entre diferentes arenas e atores". Líbero, ano XI, n. 2, p. 23-36.

MEDEIROS, Maria Lúcia (1990). Velas. Por quem? Belém: Cejup.

MIGUEL, Luis Felipe (2011). "Representação democrática: autonomia e interesse ou identidade e advocacy". Lua Nova, n. 84, p. 25-63.

(2014). Democracia e representação: territórios em disputa. São Paulo: Editora Unesp.

MOTTA-MAUÉS, Maria Angélica (2008). “Uma vez 'cria', sempre 'cria'(?): adoção, gênero e geração na Amazônia”, em LEITÃO, W. M. \& MAUÉS, R. H. (orgs.). Nortes antropológicos: trajetos e trajetórias. Belém: Editora UFPA.

(2012). "Uma mãe leva a outra(?): práticas informais (mas nem tanto) de 'circulação de crianças' na Amazônia”. Scripta Nova, v. XVI, n. 398, p. 1-24.

MPT - Ministério Público do Trabalho (2013). Pnad 2011 - Trabalho infantil doméstico no Brasil. Fortaleza: MPT.

OIT - Organização Internacional do Trabalho (2003). Boas práticas de combate ao trabalho infantil. Brasília: OIT. Disponível em: <http://www.oit. org.br/node/323>. Acessado em 10 abr. 2010.

(2004). Helping hands or shackled lives? Understanding child domestic labour and responses to it. Disponível em: $<\mathrm{http}$ ://www.ilo.org/ipecinfo/ product/viewProduct.do?productId=348>. Acessado em: 10 abr. 2010. 
(2011). Notas OIT: o trabalho doméstico remunerado na América Latina e Caribe. Disponível em: <http://www.oitbrasil.org.br/sites/ default/files/topic/gender/doc/nota_3_portugues_423.pdf $>$. Acessado em 10 abr. 2010.

OKIN, Susan Moller (2008). "Gênero, o público e o privado". Estudos Feministas, v. 16, n. 2, p. 305-32. Disponível em: <http://www.scielo.br/pdf/ ref/v16n2/02.pdf $>$. Acessado em 10 fev. 2013.

SILVA, Carla (2009). Trabalho infantil doméstico: perfil e vivência de meninas trabalhadoras em São Luís. Dissertação (mestrado) em Políticas Públicas. São Luís: Universidade Federal do Maranhão.

SPIVAK, Gayatri (2010). Pode o subalterno falar?. Belo Horizonte: Editora UFMG.

TUPIASSU, Amarílis (2005). “Amazônia, das travessias lusitanas à literatura de até agora”. Estudos Avançados, v. 19, n. 53, p. 299-320. Disponível em: $<$ http://dx.doi.org/10.1590/S0103-40142005000100019>. Acessado em 10 ago. 2012.

UNICEF - Fundo das Nações Unidas para a Infância (1999). Child domestic work. Disponível em: <http://www.unicef-irc.org/publications/265>. Acessado em 10 fev. 2007.

URBINATI, Nadia \& WARREN, Mark (2008). “The concept of representation in contemporary democratic theory". Annual Review of Political Science, n. 11, p. 387-412. Disponível em: <http://www.annualreviews.org/doi/ abs/10.1146/annurev.polisci.11.053006.190533?journalCode=polisci $>$. Acessado em 10 fev. 2010.

VELOSO, Socorro (2008). Imprensa, poder e contra-hegemonia na Amazônia: 20 anos do Jornal Pessoal (1987-2007). Tese (doutorado) em Comunicação Social. São Paulo: Universidade de São Paulo.

WAISBORD, Silvio (2009). "Can civic society change journalism? The experience of civic advocacy journalism in Latin America”. Brazilian Journalism Research, v. 5, n. 1, p. 5-21.

(2010). "The pragmatic politics of media reform: media movements and coalition-building in Latin America". Global Media and Communication, v. 6, n. 2, p. 133-53.

WEBER, Max (1991). “Os três tipos puros de dominação legítima”, em WEBER, M. Sociologia. São Paulo: Ática. 


\section{Resumo}

Este artigo analisa os limites da atuação pública de grupos de advocacy no enfrentamento ao trabalho infantil doméstico (TID), examinando o contexto paraense onde foi desenvolvido um programa de enfrentamento a esse problema. Investiga, por meio da análise crítica de discurso, a cobertura sobre a temática nos dois principais jornais locais de 2000 a 2009, com o objetivo de analisar a natureza das desigualdades relacionadas ao TID, os lugares de fala e os posicionamentos de meninas e mulheres envolvidas com o TID, e a relação apresentada entre os agentes de advocacy e as afetadas. As conclusões apontam que, apesar da contribuição do advocacy para a tematização pública desse problema, a discussão não avançou para a reflexão sobre as condições reais de autonomia dessas meninas e mulheres.

Palavras-chave: advocacy, desigualdades, trabalho infantil doméstico, gênero.

\section{Abstract}

The article analyzes the limits of advocacy groups' public actions in fighting domestic child labor (DCL). It examines the context of the Brazilian state of Pará, where a program was developed to fight the problem. Through critical discourse analysis, it investigates the coverage of the issue by the two main local newspapers from 2000 to 2009 in order to analyze: the nature of inequalities related to $D C L$; the places of speech and the stances of girls and women involved in DCL; the relationship between advocacy agents and people affected. The findings suggest that, despite the contribution of advocacy to public debate on the problem, the discussion has not advanced to a reflection on the actual conditions for those girls and women's autonomy.

Keywords: advocacy. inequalities. domestic child labor. gender.

Recebido em 31 de maio de 2015.

Aprovado em 30 de setembro de 2015. 